This is an open-access article distributed under the terms of the Creative Commons Attribution License, which permits unrestricted use, distribution, and reproduction in any medium, provided the original author(s) and source are credited.

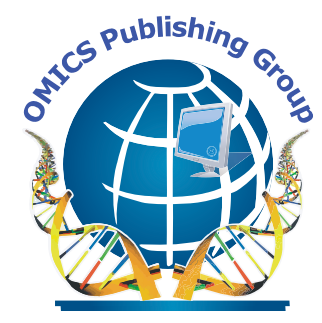

ISSN:2161-0495

Journal of Clinical Toxicologyy

The International Open Access

Journal of Clinical Toxicology

Special Issue Title:

Neuropharmacology \& Neurotoxicity

Handling Editors

Terreia S Jones

University of Tennessee Health Science Center, USA

Available online at: OMICS Publishing Group (www.omicsonline.org)

\footnotetext{
7 his article was originally published in a journal published by

1 OMICS Publishing Group, and the attached copy is provided by OMICS Publishing Group for the author's benefit and for the benefit of the author's institution, for commercial/research/educational use including without limitation use in instruction at your institution, sending it to specific colleagues that you know, and providing a copy to your institution's administrator.

All other uses, reproduction and distribution, including without limitation commercial reprints, selling or licensing copies or access, or posting on open internet sites, your personal or institution's website or repository, are requested to cite properly.
} 


\title{
Delta-9-Tetrahydrocannabinol (THC) Protects Partly against Demyelination by Modulating the Inflammatory Response: An In Vitro Study in Aggregating Brain Cell Cultures
}

Antoinette Defaux ${ }^{1}$, Mariano Schiffrin ${ }^{1}$, Lorianne Vorlet-Fawer ${ }^{1}$, Amelie SpiehImann ${ }^{1}$, Christian Giroud ${ }^{2,3}$ and Florianne Monnet-Tschudi ${ }^{1,2}$

${ }^{1}$ Department of Physiology, University of Lausanne, $\mathrm{CH}$-1005 Lausanne, Switzerland

2SCAHT (Swiss Centre for Applied Human Toxicology)

${ }^{3}$ Laboratory of Forensic Toxicology and Chemistry, University Center of Legal Medicine, Lausanne-Geneva, and University Hospital Center and University of Lausanne, Switzerland

\begin{abstract}
Delta 9-tetrahydrocannabinol (THC) has been proposed as therapeutic agent in the treatment of multiple sclerosis. In the present study, we examined whether a modulation of brain inflammation by THC may protect against demyelination. Myelinating aggregating brain cell cultures were subjected to demyelination by a repeated treatment (3x) with the two inflammatory agents interferon-y (IFN- $y$ ) and lipopolysaccharide (LPS). The effects of THC on an acute inflammatory response were also examined by treating the aggregates with a single application of the two inflammatory agents. THC effects on the demyelinating process and on several mediators of the inflammatory response were analyzed.
\end{abstract}

THC treatment partially prevented the decreased immunoreactivity for MBP, and the decrease in MBP content measured by immunoblotting. It prevented IFN- $-y+$ LPS-induced microglial reactivity; and decreased the IFN- $-\gamma+$ LPS-induced increased phosphorylation of p44/42 MAP kinase. The other inflammatory markers, i-NOS and TNF-a mRNA expression, and p38 MAP kinase phosphorylation were downregulated by THC treatment following a single application of the inflammatory agents, but not after repeated applications.

THC protected partially against the IFN- $y+$ LPS-induced demyelination. The protective effect of THC on IFN- $y+$ LPS-induced demyelination may be due to a decrease of the inflammatory response. However, the anti-inflammatory effect of THC on some inflammatory markers is lost when the inflammatory response is more prominent and of longer duration, suggesting either that the anti-inflammatory effect of a molecule may depend on the properties of the inflammatory response, or that the anti-inflammatory potential of THC decreases in case of repeated exposure.

Keywords: Demyelination; Neuroinflammation; Microglia; Cytokines; THC; MAP kinases

\section{Introduction}

Delta-9-tetrahydrocannabinol (THC) is the main psychoactive compound of cannabis. Cannabinoids have been proposed as therapeutic drugs in multiple sclerosis (MS) for both the control of spasticity and the modulation of brain inflammation [1-7]. THC interacts mainly with two receptors, cannabinoid receptor 1 (CB1) and cannabinoid receptor 2 (CB2) [8-11] CB2 was first identified in immune cells [12]. In brain, the expression of CB2 by microglial cells [13] is upregulated when they are activated [14].Recent studies show that glial cells also express cannabinoids-like receptors, which seems to be involved in the regulation of immune functions (for review, [15]). The Peroxisome Proliferator-Activated Receptors (PPARs) can be activated by cannabinoids [16] and may mediate some of their antiinflammatory effects (for review, [17]). Ajulemic acid, an analog of a metabolite of THC binds to PPAR- $\gamma$ [18], and endocannabonoids were shown to be natural activators of PPAR- $\alpha$ and PPAR- $\gamma$ [16].

The anti-inflammatory potential of THC, as well as of endogeneous and synthetic agonists of the various cannabinoid receptors has been widely reported. THC can block NO liberation in LPS-stimulated macrophages [19]. Facchinetti and collaborators [20] have shown that endogenous and synthetic cannabinoids prevented TNF- $a$ release by LPS-stimulated microglia. In astrocytes, endogenous cannabinoids have been shown to inhibit NO and TNF- $\alpha$ production induced by LPS $[21,22]$. Furthermore, cannabinoids can induce the expression of anti-inflammatory cytokines such as IL-4 and IL-10 [23]. They can inhibit neurodegeneration in models of multiple sclerosis [24] In experimental autoimmune encephalomyelitis (EAE), an animal model of MS, attenuation of the interactions between immune cells and endothelial cells by cannabinoids may be neuroprotective [25]. It has been proposed that CB2 receptor played a key role in attenuating EAE progression through modulation of the immune response [26]. Activation of the endocannabinoid system was shown to be beneficial in a chronic mice model of MS, reducing neuroinflammation, excitotoxicity and motor disability [27-29].

In the present work, serum-free aggregating brain cell cultures [30] were used as model to study the effects of THC on brain inflammation, and demyelination. In these three-dimensional cell cultures, all brain cell types (i.e., neurons, astrocytes, oligodendrocytes, and microglia) are present in proportions close to the situation in vivo, and organized in a histotypic manner. During 3-4 weeks in vitro, a

*Corresponding author: Florianne Monnet-Tschudi, Department of Physiology University of Lausanne, 7, rue du Bugnon, $\mathrm{CH}-1005$ Lausanne, Switzerland, Tel: +4121 69255 20; Fax: +41 2169255 05; E-mail: florianne.tschudi-monnet@unil.ch

Received February 08, 2012; Accepted March 26, 2012; Published March 28, 2012

Citation: Defaux A, Schiffrin M, Vorlet-Fawer L, Spiehlmann A, Giroud C, et al (2012) Delta-9-Tetrahydrocannabinol (THC) Protects Partly against Demyelination by Modulating the Inflammatory Response: An In Vitro Study in Aggregating Brain Cell Cultures. J Clinic Toxicol S6:002. doi:10.4172/2161-0495.S6-002

Copyright: @ 2012 Defaux A, et al. This is an open-access article distributed unde the terms of the Creative Commons Attribution License, which permits unrestricted use, distribution, and reproduction in any medium, provided the original author and source are credited. 
Citation: Defaux A, Schiffrin M, Vorlet-Fawer L, Spiehlmann A, Giroud C, et al. (2012) Delta-9-Tetrahydrocannabinol (THC) Protects Partly against Demyelination by Modulating the Inflammatory Response: An In Vitro Study in Aggregating Brain Cell Cultures. J Clinic Toxicol S6:002. doi:10.4172/2161-0495.S6-002

sequence of morphogenic events occur, including the formation of compact myelin around axons [31]. It is important to note that this in vitro model is devoid of lymphocytes and allows to study the role of neuroinflammation in the demyelinating and remyelinating processes in the absence of the peripheral inflammatory cells.

Previous work [32] showed that in mature aggregating brain cell cultures, the combined treatment with interferon- $\gamma$ (IFN- $\gamma$ and lipopolysaccharide (LPS), two inflammatory agents, induced microglial activation and the upregulation of a variety of inflammatory mediators including cytokines and chemokines. This inflammatory response was accompanied by demyelination in the absence of neuronal damage or cell death. In the present work, making use of this experimental paradigm, it was found that THC prevented the microglial activation triggered by the combined treatment with IFN- $\gamma$ and LPS, and partially protected against the concomitant demyelination. This protective effect may be due to a decrease of the inflammatory response. In order to further study the anti-inflammatory potential of THC, the mRNA expression of i-NOS, TNF- $\alpha$ and IL- $1 \beta$, as well as the phosphorylation state of p44/42 and p38 MAP kinases were measured after a single and a repeated $(3 \mathrm{x})$ treatment with the two inflammatory agents. In addition, the involvement of PPAR- $\gamma$ in the anti-inflammatory effects of THC was examined by using an antagonist of PPAR- $\gamma$ and by measuring the mRNA expression of PPAR- $\gamma$.

\section{Materials and Methods}

\section{Aggregating brain cell cultures}

Serum-free aggregating brain cell cultures were prepared from the telencephalon of 16-day embryonic rats (Hsd:SD, Harlan, NL-5960 AD Horst) as described previously in detail $[30,33]$. The embryonic brain tissue was mechanically dissociated using nylon sieves of $200-\mu \mathrm{m}$ and $100-\mu \mathrm{m}$ pores, and the dissociated cells were incubated under gyratory agitation in serum-free medium. The resulting aggregate cultures were maintained in serum-free medium (DMEM adjusted for serumfree conditions) under constant gyratory agitation $(80 \mathrm{rpm})$ at $37^{\circ} \mathrm{C}$ in an atmosphere of $10 \% \mathrm{CO}_{2}$ and $90 \%$ humidified air. Media were replenished by the replacement of $5 \mathrm{ml}$ of culture supernatant (of a total of $8 \mathrm{ml}$ per flask) with fresh medium every $3^{\text {rd }}$ day until day in vitro (DIV) 14 , and every $2^{\text {nd }}$ day thereafter. For experimentation, replicate cultures were prepared by randomizing and aliquoting the freefloating aggregates of the original cultures. For media replenishment in replicate cultures, aliquots of $2.5 \mathrm{ml}$ spent medium were replaced by fresh medium.

\section{Combined treatment with IFN $-\gamma$ and LPS}

A single treatment with IFN $-\gamma(50 \mathrm{U} / \mathrm{ml}$ final concentration) and LPS ( $5 \mu \mathrm{g} / \mathrm{ml}$ final concentration) was applied to investigate the effect of an acute inflammatory response. A prolonged inflammatory response and the accompanying demyelination were triggered by the repeated treatment with IFN- $\gamma(50 \mathrm{U} / \mathrm{ml}$ final concentration) and LPS $(5 \mu \mathrm{g} / \mathrm{ml}$ final concentration). The treatment, initiated at DIV 22, was repeated twice, at DIV 24 and DIV 26 (last treatment), each time after media replenishment. Stock solutions were prepared, for IFN- $\gamma$ (Peprotec) in phosphate buffered saline (PBS) containing $0.1 \%$ bovine serum albumin ( $\mathrm{pH} 8$ ), and for LPS (Sigma) in $0.9 \% \mathrm{NaCl}$.

\section{THC and GW9662 treatments}

Stock solutions of (-)- $\Delta^{9}$-Tetrahydrocannabinol (THC) at a concentration of $1.0 \mathrm{mg} / \mathrm{ml}$ ethanol were purchased from Lipomed AG, Arlesheim, Switzerland. THC final concentration was chosen according to Monnet-Tschudi et al. [34]. THC ( $1 \mu \mathrm{M}$ final concentration) was given simultaneously with the inflammatory agents IFN- $\gamma$ and LPS, from a $10^{3}$-fold concentrated stock solution prepared in Ethanol. GW9662 (2-Chloro-5-nitro- $N$-phenylbenzamide) was obtained from Tocris bioscience, Lucerna chem. AG., Lucerne, Switzerland. GW9662 ( $2 \mu \mathrm{M}$ final concentration, chosen according to Zurich et al., [35]) was applied alone or together with THC 1 hour before the inflammatory agents from a $10^{3}$-fold concentrated stock solution prepared in Ethanol.

\section{Western blot analysis}

Cultures were washed twice with PBS at $4^{\circ} \mathrm{C}$. Western Blot analysis were done according to pervious publications $[32,36]$. Aggregates were homogenized in lysis buffer (10 mM Tris- $\mathrm{HCl}$ ph 7.5, 6M Urea, $0.1 \%$ SDS, 1/100 Complete protease inhibitor, and 1/100 sodium-orthovanadate). The protein content was measured by the BCA assay. Per well, 40 to $60 \mu \mathrm{g}$ of protein was loaded. Blots were stripped (Re-Blot Plus Mild antibody stripping solution; Chemicon) and incubated with antibody against $\beta$ actin (1/30000; Sigma) to demonstrate equal loading of protein in each lane. The autoradiograms were scanned and processed by image analysis (Quantity One, BioRad). Data were acquired in arbitrary densitometric units and transformed to percentages of densitometric levels obtained from scans of control samples visualized on the same blot.

\section{Quantitative RT-PCR}

Aggregating brain cell cultures were washed twice with $5 \mathrm{ml}$ of icecold PBS, and the pellet stored at $-80^{\circ} \mathrm{C}$. The RNeasy kit from Qiagen was used to extract total RNA. The reverse transcription (RT) reaction was performed using the High capacity cDNA Reverse Transcription Kit and protocols from Applied Biosystem (ABI, Foster City, CA, USA). Briefly, the RT was run with $2 \mu \mathrm{g}$ of total RNA in a reaction volume of $20 \mu \mathrm{l}$. Aliquots of this reaction mixture were used for the subsequent PCR reactions. The expression of iNOS was quantified using SYBR Green (ABI), whereas the expression of IL-1 $\beta$, IL- 6 and TNF- $\alpha$ was quantified using Taqman gene expression assay (ABI) as previously published [32,35].

\section{Immunocytochemical and Isolectin B4 stainings}

Aggregating brain cell cultures were washed twice with pre-warmed PBS, embedded in cryomatrix (Jung, Nussloch, Germany), frozen in isopentane cooled with liquid nitrogen, and stored at $-80^{\circ} \mathrm{C}$. For immunocytochemistry, cryosections $(10 \mu \mathrm{m})$ were fixed for 15 minutes in $4 \%$ paraformaldehyde dissolved in PBS at room temperature, and then washed in PBS. For blockade of non-specific binding, sections were first incubated in normal horse serum (1/25 in PBS with $0.1 \%$ Triton-X100, Jackson) and exposed overnight at $4^{\circ} \mathrm{C}$ to antibodies against MBP (mouse monoclonal, 1/40, Chemicon). Sections were then incubated with the horse anti-mouse biotinylated IgG (1/200, Vector) and mounted in ProLong Gold antifade reagent (Invitrogen). For the staining of microglia by the specific binding of FITC-conjugated isolectin B4 of Griffonia simplicifolia (IB4), cryosections were washed for 15 minutes in Tris buffer containing 1\% Triton X-100 and then incubated for 30 minutes in Image-iT FX signal enhancer (Invitrogen). Sections were then exposed overnight at $4^{\circ} \mathrm{C}$ to IB4 (1/500, Sigma). Image $\mathrm{J}$ software was used to quantify the labeled area of aggregate sections. Sections from the central area of aggregates were taken for analysis. Threshold of fluorescence was defined and set up in some images of the control untreated cultures in order to cover all labeled area above background, and was applied to all images of the different treatments. Only changes in labelled area are reported here. Results are expressed as percentage of untreated control cultures. 
Citation: Defaux A, Schiffrin M, Vorlet-Fawer L, Spiehlmann A, Giroud C, et al. (2012) Delta-9-Tetrahydrocannabinol (THC) Protects Partly against Demyelination by Modulating the Inflammatory Response: An In Vitro Study in Aggregating Brain Cell Cultures. J Clinic Toxicol S6:002. doi:10.4172/2161-0495.S6-002

\section{Statistics}

Data are expressed as mean \pm standard error of the mean (SEM). For western blot analysis, data are expressed as percentages of untreated control cultures and each value is the average of 8-9 replicate cultures obtained in 3 independent experiments, using cultures of different batches. Data were statistically evaluated for significance by the Kruskal-Wallis test followed by the Mann-Whitney test using StatA software. For quantitative RT-PCR, data are expressed as fold changes of untreated control cultures, and each value is the average of 6-8 replicate cultures of 3-4 independent experiments. Data were also statistically evaluated for significance by the Kruskal-Wallis test followed by the Mann-Whitney test. For immunostaining, data are expressed as percentages of untreated control cultures, and each value is the average of the quantification of 20 aggregate images from one experiment. The analysis of 3 independent experiments produced similar results. Data were statistically evaluated by one-way ANOVA followed by the Tukey post-test.

\section{Results}

Aggregating brain cell cultures were treated from DIV 22 to DIV 26 with the two inflammatory agents, IFN- $\gamma(50 \mathrm{U} / \mathrm{ml})$ and LPS $(5 \mu \mathrm{g} /$ $\mathrm{ml})$. THC $(1 \mu \mathrm{M})$ was given simultaneously with the administration of the two inflammatory agents. The effects of THC on demyelination were assessed by measuring MBP expression and content by immunocytochemistry and immunoblotting, respectively.

Cultures treated with IFN- $\gamma$ and LPS exhibited strongly decreased MBP immunostaining (Figure $1 \mathrm{C}$ vs $\mathrm{A}$, and $\mathrm{E}$ ) indicating that demyelination occurred. THC together with the inflammatory agents partially prevented the decreased immunoreactivity for MBP (Figure 1, D vs. C, and E). In the absence of the inflammatory stimulation, THC did not modify the immunoreactivity for MBP (Figure $1 \mathrm{~B}$ vs A). These findings were confirmed by western blot analysis for MBP (Figure 2). Treatment with the demyelinating agents strongly reduced MBP content (Figure $2 \mathrm{~A}$ and $\mathrm{B}$ ) and the addition of THC partially prevented the decrease in MPB content (Figure $2 \mathrm{~A}$ and $\mathrm{C}$ ). In the absence of the inflammatory stimulation, THC did not alter the MBP content (Figure 2). These observations taken together indicate that THC partially prevented the demyelination triggered by the inflammatory agents.

To investigate how THC can protect against demyelination, its effects on the inflammatory response induced by IFN- $\gamma$ and LPS were examined. The extent of the inflammatory reactions was evaluated taking as criteria IB4 staining, and the expression of i-NOS, TNF- $\alpha$ and IL-1 $\beta$. To investigate the effects of THC on the mRNA expression of the inflammatory mediators, THC was applied simultaneously with the repeated treatment with IFN- $\gamma$ and LPS (3X) and also with a single treatment with the inflammatory agents.

The results (Figure 3) show that the combined treatment with the two inflammatory agents significantly increased IB4 staining (Figure 3 ), indicating microglial activation as previously descibed $[37,38]$. Addition of THC reduced the IB4 staining to the level of untreated controls (Figure 3), indicating that THC prevented the activation of microglial cells by the pro-inflammatory treatment. In the absence of the inflammatory stimulus, THC did not affect IB4 staining (Figure 3).

A single and a repeated application of the inflammatory agents strongly upregulated the mRNA expression of i-NOS (Figure 4A), TNF- $\alpha$ (Figure 4B), and IL- $1 \beta$ (Figure 4C). I-NOS and TNF- $\alpha$ expression, were more upregulated after the repeated treatment (Figure $4 \mathrm{~A}$ and $\mathrm{B}$, black bars $v s$ white bars), whereas IL-1 $\beta$ expression was more upregulated after the single treatment (Figure 4C, black bars $v s$ white bars). When cultures were treated only once, the addition of THC significantly decreased the upregulation of i-NOS and tended to reduced TNF- $\alpha$ expression (Figure $4 \mathrm{~A}$ and B, white bars), whereas it did no affect significantly IL- $1 \beta$ increased expression (Figure $4 \mathrm{C}$, white bars). When the treatments were repeated, THC did not decrease i-NOS, TNF- $\alpha$ and IL- $1 \beta$ upregulated expression (Figure 4 , black bars). In the absence of the inflammatory stimulus, THC did not affect i-NOS, TNF- $\alpha$ and IL- $1 \beta$ expression (Figure 4 ).

To further investigate the modulation of the inflammatory cascade, changes in the phosphorylation of $44 / 42$ (Erk1/2) and p38 MAP kinases were examined by western blot analysis. The results (Figure 5) show that the treatment of cultures with the two inflammatory agents given either once or three times significantly increased the phosphorylation of p44/42 MAP kinase (Figure 5A, B, D) and of p38 MAP kinase (Figure
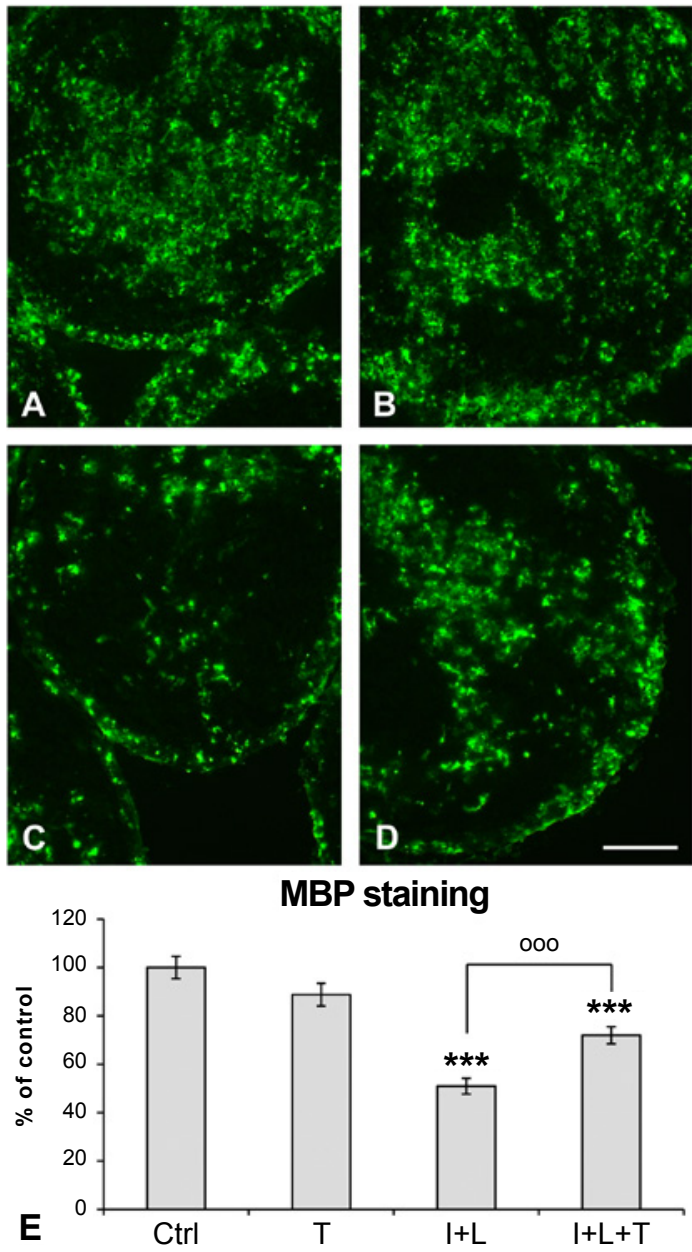

Figure 1: Effects of THC on MBP immunostaining.

Aggregate cultures remained either untreated $(A)$, or were treated with THC $(1 \mu \mathrm{M})(\mathrm{B})$; IFN-Y $(50 \mathrm{U} / \mathrm{ml})$ plus LPS $(5 \mu \mathrm{g} / \mathrm{ml})(\mathrm{C})$; or treated with THC simultaneously with the inflammatory agents (D). Cultures were harvested 48 hours after the last treatment with the inflammatory agents. The MBP staining was quantified $(E)$, measuring 20 aggregate sections per treatment and expressing the stained area as percent of untreated control cultures. The Figure shows representative data from one experiment. Results were statistically evaluated for significance by one-way ANOVA test followed by the Tukey post-test. $\left({ }^{*} \mathrm{P}<0.05\right.$, ${ }^{* * *} \mathrm{P}<0.001$, compared with untreated control cultures; ${ }^{\circ \circ} \mathrm{P}<0.001$ compared with cultures treated with the inflammatory agents). Bar $=100 \mu \mathrm{m}$. 
Citation: Defaux A, Schiffrin M, Vorlet-Fawer L, Spiehlmann A, Giroud C, et al. (2012) Delta-9-Tetrahydrocannabinol (THC) Protects Partly against Demyelination by Modulating the Inflammatory Response: An In Vitro Study in Aggregating Brain Cell Cultures. J Clinic Toxicol S6:002. doi:10.4172/2161-0495.S6-002

Page 4 of 8

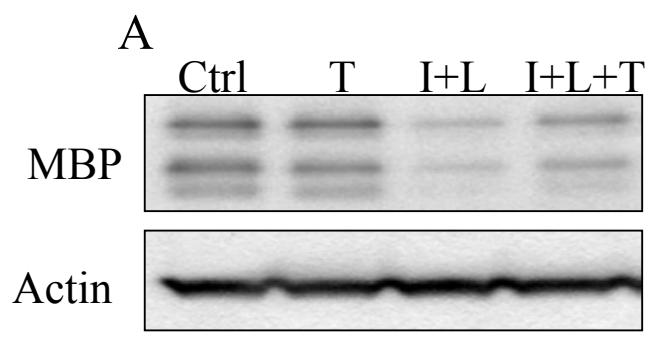

\section{B MBP content}
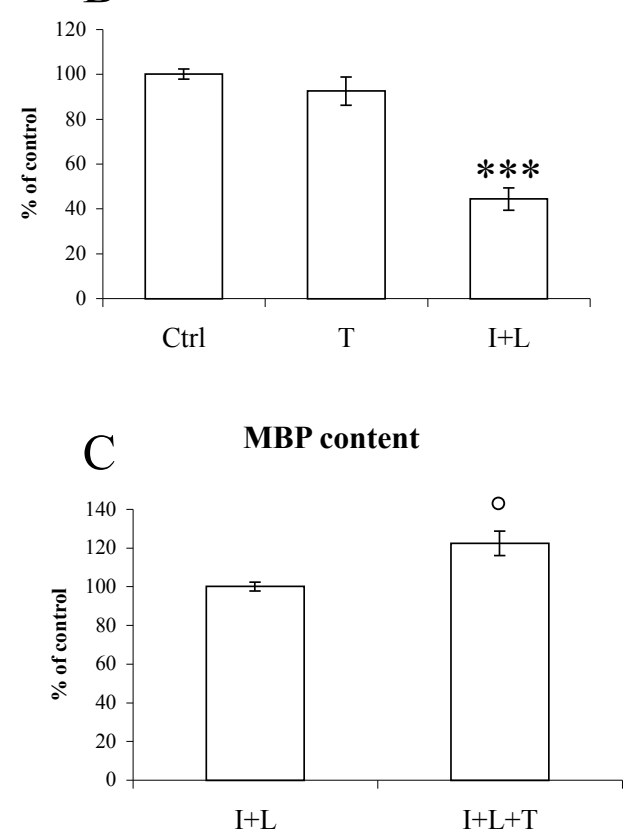

Figure 2: Effects of THC on the MBP content.

Panel A shows representative western blots of MBP and $\beta$-actin. Panel B shows quantification of the MBP content expressed as percentage of untreated control cultures $(=100 \%)$. Panel C shows quantification of the MBP content expressed as percentage of cultures treated with the inflammatory agents $(=100 \%)$ Cultures were harvested 48 hours after the last IFN-y plus LPS treatment Measuring $\beta$-actin assessed equal loading of protein. Each value is the mean of 9 replicate cultures. Results were statistically evaluated for significance by the Kruskal-Wallis test followed by the Mann-Whitney test. ${ }^{* * *} P<0.001$, compared with untreated control cultures; ${ }^{\circ} \mathrm{P}<0.01$ compared with cultures treated with the inflammatory agents).

5A and F). However, p38 MAP kinase phosphorylation was much more increased after a repeated exposure. When the treatment was applied only once, this increase in phosphorylation was significantly attenuated in presence of THC for both p44/42 MAP kinase (Figure 5A, C, E, white bars) and p38 MAP kinase (Figure 5A, G, white bars). When the treatment was repeated, THC still decreased the phosphorylation of p44/42 MAP kinase (Figure 5A, C, E, black bars), but had no effect on the increased phosphorylation of p38 (Figure 5A, G, black bars). THC alone did not modify the basal level of phosphorylation of these MAP kinases (Figure 5A, B, D).

In order to examine whether an activation of cannabinoid-like receptors and in particular of PPAR- $\gamma$ may be involved in the antiinflammatory effect of THC observed in the acute neuroinflammation, the irreversible PPAR- $\gamma$ antagonist GW9662 $(2 \mu \mathrm{M})$ was applied alone or together with THC 1 hour before the inflammatory agents.
GW9662 applied simultaneously with THC did not block the THCinduced decrease in i-NOS mRNA expression observed after the single application of IFN- $\gamma+$ LPS. Even, when applied alone, it decreased the IFN- $\gamma+$ LPS-induced upregulation of i-NOS mRNA after the single treatment with the inflammatory agents and lost this effect after the repeated treatment (Figure $6 \mathrm{~A}$ ). Similar observations were made for TNF- $\alpha$ (not shown). To further investigate the role of PPAR- $\gamma$ in the THC-induced modulation of the inflammatory response, the mRNA expression of PPAR- $\gamma$ was measured. It was found that IFN- $\gamma+$ LPS tended to decrease PPAR- $\gamma$ mRNA expression and that THC and GW9662 applied alone did not modify this response (Figure $6 \mathrm{~B}$ ). When THC and GW9662 were applied together, PPAR- $\gamma$ mRNA expression returned to control level after the acute treatment with the inflammatory agents (Figure 6B). No modification of PPAR- $\gamma$ mRNA expression by THC and GW9662 applied alone or together were observed after the repeated treatment with the inflammatory agents (Figure 6B).

\section{Discussion}

In multiple sclerosis, beneficial effect of cannabinoids on symptomatic spasms and pain have been evidenced by several clinical trials [39-41]. Whether disability progression can be slowed by cannabinoid treatments remained to be demonstrated [41] Experimental studies aim at studying the mechanisms underlying the efficacy of cannabinoids treatments. In the present study we showed that THC partially protects against INF- $\gamma$ and LPS-induced demyelination. We have then investigated whether this protective effect was mediated by a modulation of the neuroinflammatory response.

As expected, IFN- $\gamma+$ LPS-induced microglial reactivity was downregulated by THC. But THC decreased the mRNA expression of i-NOS and TNF- $\alpha$ only after the single treatment with the inflammatory agents, but not after the repeated one. Regarding the MAP kinase pathways, that are involved in the inflammatory response [42], the increased phosphorylation of $\mathrm{p} 44 / 42$ was attenuated by THC after both acute and repeated IFN- $\gamma+$ LPS treatment, whereas p38

\section{IB4 staining}

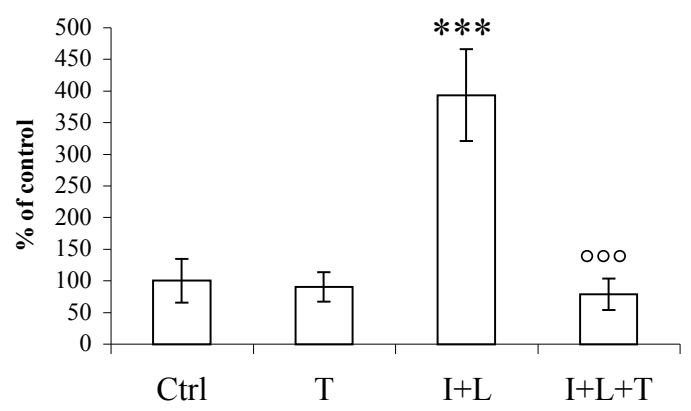

Figure 3: Effects of THC on microglial activation.

Aggregate cultures remained either untreated [Ctrl] or were treated with $\mathrm{THC}$ $(1 \mu \mathrm{M})[\mathrm{T}] ;$ IFN-Y $(50 \mathrm{U} / \mathrm{ml})$ plus LPS $(5 \mu \mathrm{g} / \mathrm{ml})[\mathrm{l}+\mathrm{L}]$; or treated with THC simultaneously with the inflammatory agents $[\mathrm{I}+\mathrm{L}+\mathrm{T}]$. Cultures were harvested 48 hours after the last treatment with the inflammatory agents. The IB4 labelled microglial cells were quantified by measuring 20 aggregate sections per treatment and expressing the stained area as percent of untreated control cultures. The Figure shows representative data from one experiment. Results were statistically evaluated for significance by one-way ANOVA test followed by the Tukey post-test. ( ${ }^{* * *} \mathrm{P}<0.001$ compared with untreated control cultures; ${ }^{\circ 0} \mathrm{P}<0.001$ compared with to cultures treated with the inflammatory agents). 
Citation: Defaux A, Schiffrin M, Vorlet-Fawer L, Spiehlmann A, Giroud C, et al. (2012) Delta-9-Tetrahydrocannabinol (THC) Protects Partly against Demyelination by Modulating the Inflammatory Response: An In Vitro Study in Aggregating Brain Cell Cultures. J Clinic Toxicol S6:002. doi:10.4172/2161-0495.S6-002

A

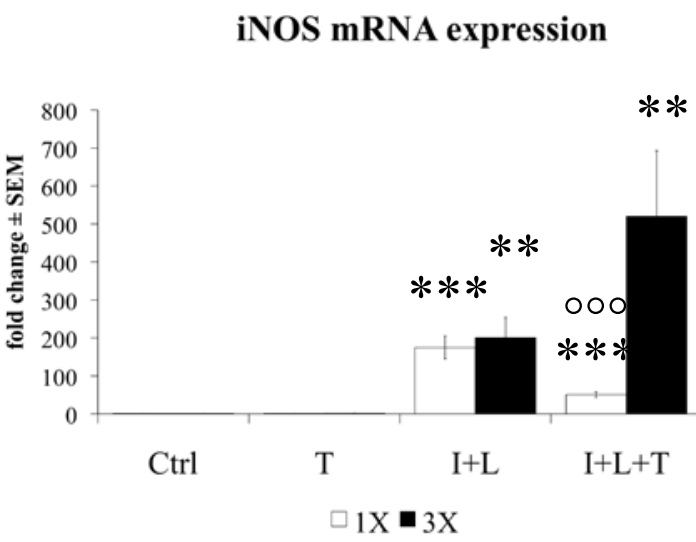

$\mathrm{B}$

TNF- $\alpha$ mRNA expression

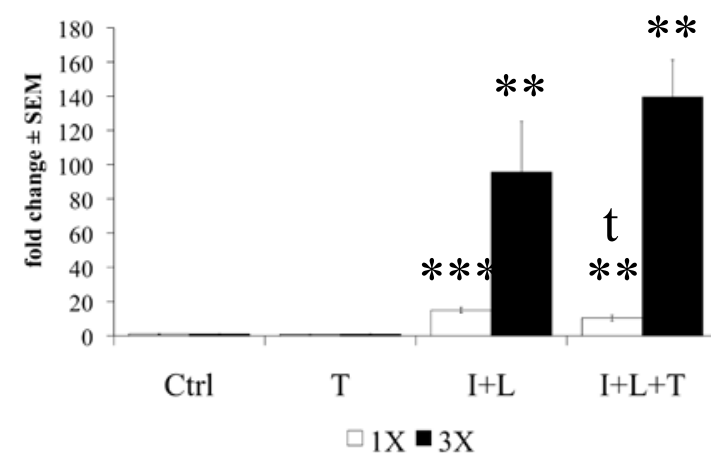

IL-1; mRNA expression

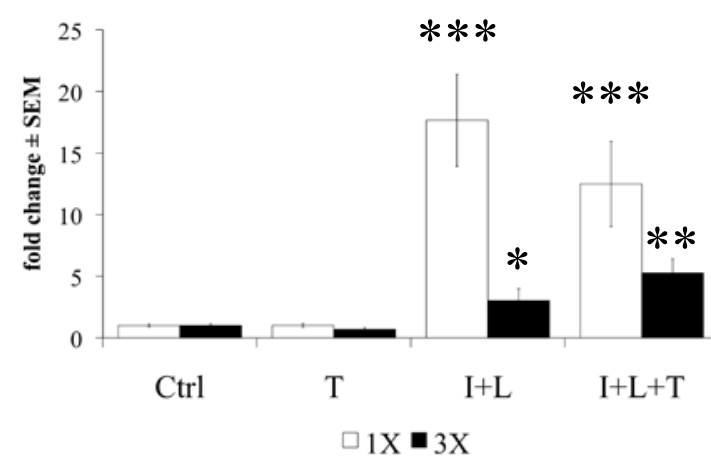

Figure 4: Effects of THC on iNOS (A), TNF- $\alpha$ (B) and IL-1 $\beta$ (C) mRNA expression.

Aggregate cultures remained either untreated [Ctrl] or were treated with $\mathrm{THC}$ $(1 \mu \mathrm{M})[\mathrm{T}]$; IFN-Y $(50 \mathrm{U} / \mathrm{ml})$ plus LPS $(5 \mu \mathrm{g} / \mathrm{ml})[\mathrm{I}+\mathrm{L}]$; or treated with THC simultaneously with the inflammatory agents $[I+L+T]$. These treatments were applied one time $(1 \mathrm{X})$ or three times $(3 \mathrm{X})$. For measuring the mRNA expression, cultures were harvested 24 hours after the inflammatory treatments. Values are expressed as fold change of untreated control cultures $(=1)$, each value being the mean of 6-8 replicate cultures. Results were statistically evaluated for significance by the Kruskal-Wallis test followed by the Mann-Whitney test. $\left({ }^{*} \mathrm{P}<0.05,{ }^{* *} \mathrm{P}<0.01,{ }^{* * *} \mathrm{P}<0.001\right.$ compared with untreated control cultures ${ }^{\circ 0 \circ} \mathrm{P}<0.001$ compared to cultures treated with the inflammatory agents; $\mathrm{t}=$ tendancy compared to cultures treated with the inflammatory agents $(P=$ $0.0742))$.

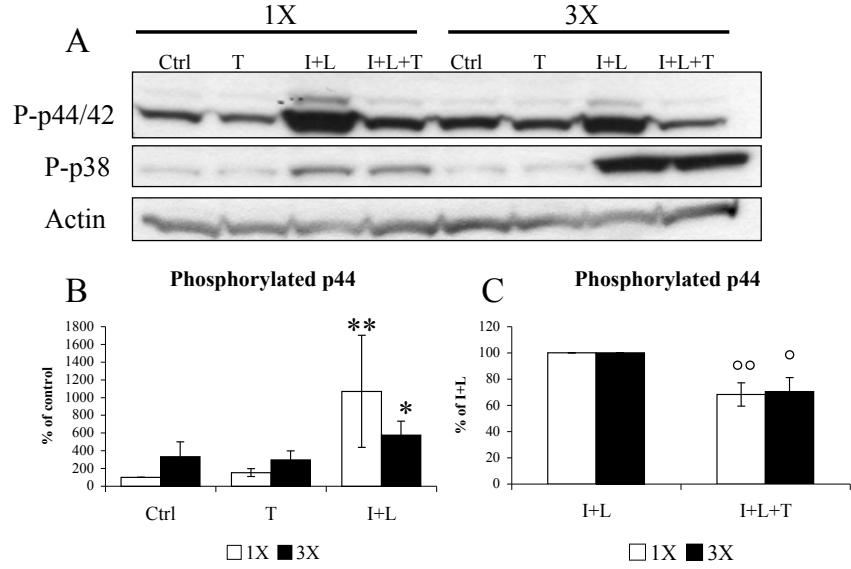

Phosphorylated p42

Phosphorylated p42
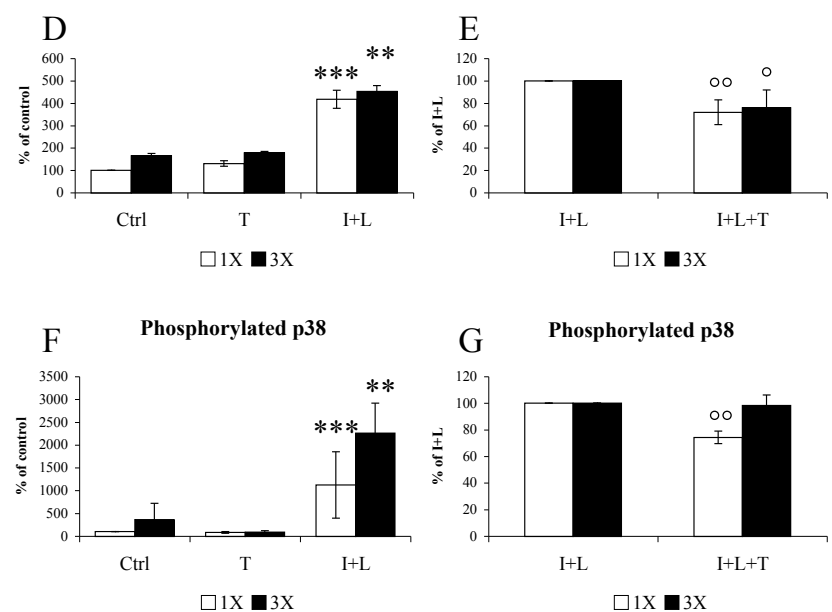

Figure 5: Effects of THC on p44/42 and p38 phophorylation.

Aggregate cultures remained either untreated [Ctrl] or were treated with $\mathrm{THC}$ $(1 \mu \mathrm{M})[\mathrm{T}] ;$ IFN-Y $(50 \mathrm{U} / \mathrm{ml})$ plus LPS $(5 \mu \mathrm{g} / \mathrm{ml})[\mathrm{l}+\mathrm{L}]$; or treated with THC simultaneously with the inflammatory agents $[I+L+T]$. These treatments were applied one time $(1 \mathrm{X})$ or three times $(3 \mathrm{X})$. Panel A shows representative western blots for phophorylated-p44/42 [P-p44/42], phophorylated-p38 [Pp38], and actin. Panels B, D, and F show quantification of phophorylated-p44, phosphorylated-p42 and p38, respectively, expressed as percentage of untreated control cultures $(=100 \%)$. Panels $C, E$, and $G$ show quantification of phophorylated-p44, p42 and p38, respectively, expressed as percentage of cultures treated with the inflammatory agents $(=100 \%)$. Cultures were harvested 24 hours after the treatments. Measuring $\beta$-actin expression assessed equal loading of protein. Each value is the mean of $8-9$ replicate cultures. Results were statistically evaluated for significance by the Kruskal-Wallis test followed by the Mann-Whitney test. $\left({ }^{*} P<0.05,{ }^{* *} P<0.01,{ }^{* * *} P<0.001\right.$ compared with untreated control cultures; ${ }^{\circ} \mathrm{P}<0.05,{ }^{\circ} \mathrm{P}<0.01$ compared with cultures treated with the inflammatory agents.

phosphorylation was decreased only after the single application of IFN- $\gamma+$ LPS. P38 MAP kinase is implicated in the signal transduction pathway responsible for the increased expression of i-NOS and TNF- $a$ $[43,44]$. Therefore, the decrease in i-NOS and TNF- $\alpha$ expression induced by THC could be related to the decreased activation of $\mathrm{p} 38$. Although p44/42 signaling plays also a role in i-NOS expression in microglia [43-45], it appears that after a repeated treatment with the inflammatory agents, the attenuation of $\mathrm{p} 44 / 42$ phosphorylation by THC was not sufficient to modulate i-NOS expression.

The lack of effect of THC on i-NOS and TNF- $\alpha$ expression and on p38 activation after the repeated exposure to the inflammatory agents could be due to the repeated application of THC leading to an 


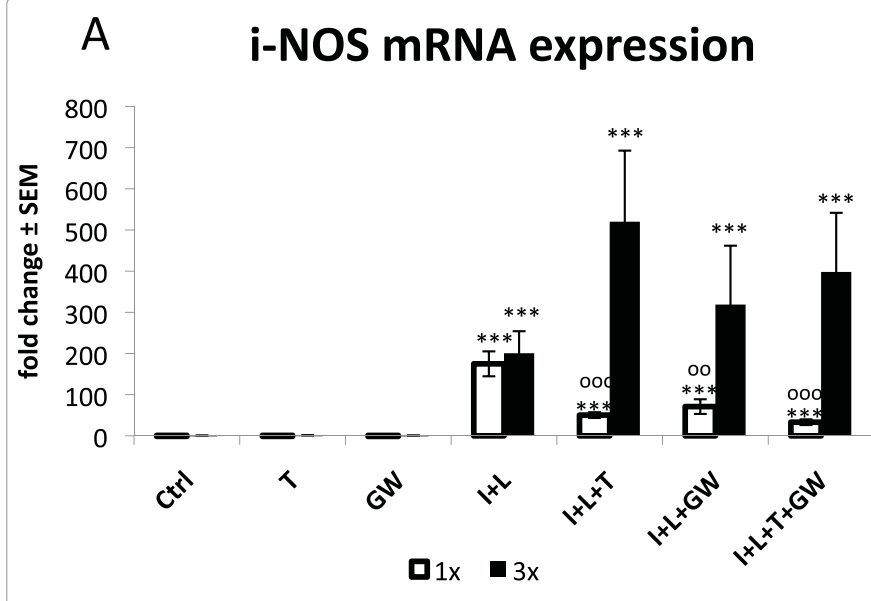

\section{B PPAR- $\gamma$ mRNA expression}

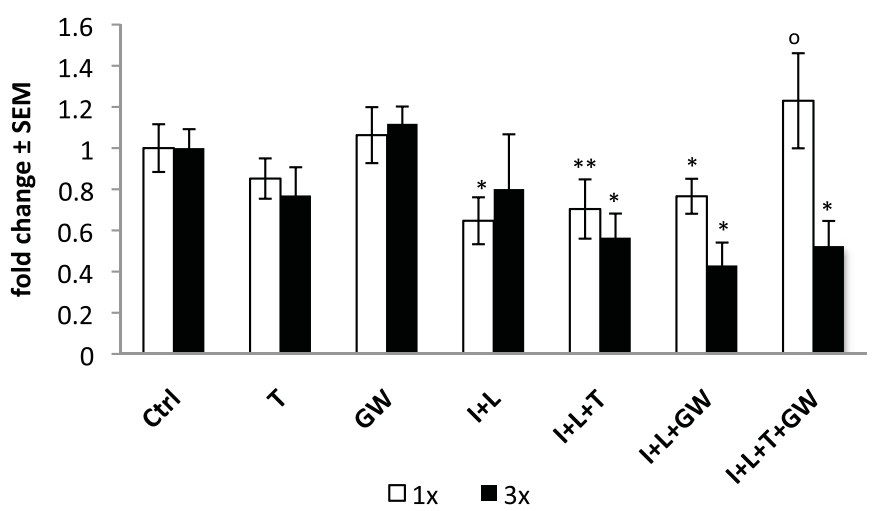

Figure 6:

A. Effects of THC and of the PPAR-y antagonist GW9662 on IFN- $\mathrm{Y}+\mathrm{LPS}$ induced mRNA expression of i-NOS

Aggregate cultures remained either untreated or were treated with $\mathrm{THC}(1 \mu \mathrm{M})$ or GW9662 $(2 \mu \mathrm{M})$. GW9662 and THC were applied 1 hour before IFN-y (50 $\mathrm{U} / \mathrm{ml}$ ) plus LPS $(5 \mu \mathrm{g} / \mathrm{ml})$. These treatments were applied once $(1 \mathrm{x})$ or three times $(3 \mathrm{x})$. For measuring the mRNA expression, cultures were harvested 24 hours after the inflammatory treatments. Values are expressed as fold change of untreated control cultures $(=1)$, each value being the mean of 8 replicate cultures. Results were statistically evaluated for significance by the KruskalWallis test followed by the Mann-Whitney test. ( $\mathrm{P} P<0.05,{ }^{* *} \mathrm{P}<0.01,{ }^{* \prime *} \mathrm{P}<0.001$ compared with untreated control cultures; ${ }^{\circ 0} \mathrm{P}<0.001$ compared with to cultures treated with the inflammatory agents).

B. Effects of THC on PPAR- y mRNA expression

Aggregate cultures remained either untreated or were treated with THC $(1 \mu \mathrm{M})$ or GW9662 (2 mM). GW9662 and THC were applied 1 hour before IFN-y (50 $\mathrm{U} / \mathrm{ml}$ ) plus LPS $(5 \mathrm{mg} / \mathrm{ml})$. These treatments were applied once $(1 \mathrm{x})$ or three times $(3 \mathrm{x})$. For measuring the mRNA expression, cultures were harvested 24 hours after the inflammatory treatments. Values are expressed as fold change of untreated control cultures $(=1)$, each value being the mean of 5 replicate cultures. Results were statistically evaluated for significance by the KruskalWallis test followed by the Mann-Whitney test. ( $\mathrm{P}<0.05$, ${ }^{\text {"* }} \mathrm{P}<0.01$, compared with untreated control cultures; ${ }^{\circ} \mathrm{P}<0.05$ compared to cultures treated with the inflammatory agents).

internalization of cannabinoid receptors [46,47]. A single application of THC given with the last (third) treatment with the inflammatory agents tended to downregulate IL1 $\beta$ mRNA expression (P value 0.09 ), caused a small but not significant decrease of i-NOS mRNA expression, whereas TNF- a remained unchanged (data not shown), suggesting that internalization might occur. However, microglial activation, induced by a repeated treatment with the inflammatory agents, was reduced by the repeated application of THC. This effect may be mediated by CB2 receptors [48] that are more abundant on these cells when activated [13-14], and that are probably present in the cultures as assessed by measuring the mRNA expression (not shown). However, application of the CB2 and CB1 receptor antagonists, AM630 $(1 \mu \mathrm{M})$ and AM251 (1 $\mu \mathrm{M})$, respectively, one hour before the application of IFN- $\gamma+$ LPS and THC did not block the anti-inflammatory effect of THC observed after a single application of the anti-inflammatory agents (not shown). But the anti-inflammatory effects of THC can also be mediated by CB-like receptors, mainly those related to high concentrations of THC $(1 \mu \mathrm{M})$ [15], such as used in this study. While THC at very high concentration $(5 \mu \mathrm{M})$ induced an upregulation of PPAR- $\gamma$ mRNA expression (data not shown), the concentration used here did nor modify PPAR- $\gamma$ mRNA expression neither in the resting conditions, nor after IFN- $\gamma$ + LPS treatments. Treatments with the inflammatory agents decreased PPAR- $\gamma$ mRNA expression, as previously described in microglial cells and astrocytes $[49,50]$. To further test the involvement of PPAR- $\gamma$ in the anti-inflammatory effect of THC, we examined whether the non reversible antagonist of PPAR- $\gamma$, GW9662, could block the THCinduced decrease of i-NOS expression in the acute inflammatory response. GW9662 not only did not block the anti-inflammatory effect of THC, but even behaved similarly than THC, it decreased i-NOS and TNF- $\alpha$ mRNA expression in case of the single treatment with IFN- $\gamma+$ LPS, and lost this effect in case of the repeated treatment. Paradoxical anti-inflammatory effect of GW9662 has been observed in a monocyte cell line [51]. The authors discussed these paradoxical results by suggesting that GW9662 could also function as a partial agonist for PPAR- $\alpha$, that was reported to be also anti-inflammatory [52,53]; or that the effects of GW9662 may be mediated though mechanisms other than the canonical pathway of PPAR- $\gamma$ activation. When the PPAR- $\gamma$ antagonist and THC were applied together, the expression of PPAR- $\gamma$ mRNA returned to control levels in case of the single treatment with IFN- $\gamma+$ LPS, suggesting synergic effects of PPAR- $\gamma$ antagonist and THC.

The differential effects of THC and GW9662 in the acute versus the prolonged inflammatory responses triggerred by a single or a repeated treatment with IFN- $\gamma+$ LPS, respectively, could signify that the characteristics of neuroinflammation change with time. In line with this hypothesis is the paper of Janabi and coworkers [54], that showed that acute and prolonged stimulation of microglia and astrocytes with IFN- $\gamma$, IL- $1 \beta$ and TNF- $\alpha$ caused differential expression of several inflammatory mediators, resulting in different activation states.

In summary, the THC-induced protection against IFN- $\gamma+$ LPSinduced demyelination appeared to be due to the anti-inflammatory potential of THC. However, the protection against demyelination was only partial. This could be related to the temporal changes in the anti-inflammatory effect of THC. Indeed, in the acute inflammatory response, all the inflammatory markers considered were decreased, whereas, when inflammation was more prominent and of longer duration, cytokines mRNA expression and p38 phosphorylation were no more downregulated by THC. This attenuation in the inflammatory potential could be due either to changes in the properties of the inflammatory response or to the repeated application of THC.

The consequences of an anti-inflammatory treatment on a demyelinating insult appeared very variable. Previous studies have shown that minocycline, an antibiotic known to decrease microglial reactivity [55] did not protect against demyelination, but favour remyelination [38]. And an agonist of PPAR- $\beta$, that showed a clear anti-inflammatory effect, did not protect against antibody-mediated demyelination [56]. Taken together, these results emphasize the central 
Citation: Defaux A, Schiffrin M, Vorlet-Fawer L, Spiehlmann A, Giroud C, et al. (2012) Delta-9-Tetrahydrocannabinol (THC) Protects Partly against Demyelination by Modulating the Inflammatory Response: An In Vitro Study in Aggregating Brain Cell Cultures. J Clinic Toxicol S6:002. doi:10.4172/2161-0495.S6-002

Page 7 of 8

role of neuroinflammation in the demyelinating and remyelinating processes, but also the difficulty to predict the beneficial effects of an anti-inflammatory treatment in therapeutic interventions.

Beside the ability to decrease neuroinflammation, cannabinoidinduced immunosuppression may also be associated with a reduction of $\mathrm{T}$ cells responsiveness or with an increased myeloid progenitor trafficking towards the inflammed foci (for review, [57]). For a therapeutic application, it remained to be demonstrated whether a protective or reparative effect of THC is achieved when applied after the demyelinating insult or continuously as a preventive treatment. However, long term treatments with relatively high concentrations was shown to induce neurotoxic effects [34], limiting a long term therapeutic use of THC.

\section{Acknowledgements}

The excellent technical assistance of Ms Brigitte Delacuisine and Denise Tavel is greatly acknowledged. This work was supported by a grant of the Swiss Society for Multiple Sclerosis to F.M.T.

\section{References}

1. Achiron A, Miron S, Lavie V, Margalit R, Biegon A (2000) Dexanabinol (HU211) effect on experimental auroimmune encephalomyelitis: implications for the treatment of acute relapses of multiple sclerosis. J Neuroimmunol 102: 26-31.

2. Arévalo-Martín A, Vela JM, Molina-Holgado E, Borrell J, Guaza C (2003) Therapeutic action of cannabinoids in a murine model of multiple sclerosis. $J$ Neurosc 23: 2511-2516.

3. Baker D, Pryce G, Croxford JL, Brown P, Pertwee RG, et al. (2000) Cannabinoids control spasticity and tremor in a multiple sclerosis model. Nature 404: 84-87.

4. Baker D, Pryce G, Giovannoni G, Thompson AJ (2003) The therapeutic potential of cannabis. Lancet Neurol 2: 291-298.

5. Iskedjian M, Bereza B, Gordon A, Piwko C, Einarson TR (2007) Meta-analysis of cannabis based treatments for neuropathic and multiple sclerosis-related pain. Curr Med Res Opin 23: 17-24.

6. Pryce G, Baker D (2007) Control of spasticity in a multiple sclerosis model is mediated by CB1, not CB2, cannabinoid receptors Br J Pharmacol 150: 519525 .

7. Marchalant Y, Rosi S, Wenk GL (2007) Anti-inflammatory property of the cannabinoid agonist WIN-55212-2 in a rodent model of chronic brain inflammation. Neuroscience 144: 1516-1522.

8. Herkenham M, Lynn AB, Little MD, Johnson MR, Melvin LS (1990) Cannabinoid receptor localization in brain. Proc Natl Acad Sci U S A 87: 1932-1936.

9. Stella N (2004) Cannabinoid signaling in glial cells. Glia 48: 267-277.

10. Ramírez BG, Blázquez C, Gómez del Pulgar T, Guzmán M, de Ceballos ML. (2005) Prevention of Alzheimer's disease pathology by cannabinoids: neuroprotection mediated by blockade of microglial activation. J Neurosci 25: 1904-1913.

11. Gong JP, Onaivi ES, Ishiguro H, Liu QR, Tagliaferro PA,et al. (2006) Cannabinoid CB2 receptors: immunohistochemical localization in rat brain. Brain Res 1071:10-23.

12. Munro S, Thomas KL, Abu-Shaar M (1993) Molecular characterization of a peripheral receptor for cannabinoids. Nature 365: 61-65.

13. Carrier EJ, Patel S, Hillard CJ (2005) Endocannabinoids in neuroimmunology and stress. Curr Drug Targets CNS Neurol Disord 4: 657-65.

14. Carlisle SJ, Marciano-Cabral F, Staab A, Ludwick C, Cabral GA (2002) Differential expression of the CB2 cannabinoid receptor by rodent macrophages and macrophage-like cells in relation to cell activation. Intern. Immunopharmacol 2: 69-82.

15. Stella N (2010) Cannabinoid and cannabinoid-like receptors in microglia, astrocytes, and astrocytomas. Glia 58: 1017-1030.

16. O'Sullivan SE (2007) Cannabinoids go nuclear: evidence for activation of peroxisome proliferator-activated receptors. Br J Pharmacol 152: 576-582.

17. O'Sullivan, SE, Kendall DA (2010) Cannabinoid activation of peroxisome proliferator-activated receptors: potential for modulation of inflammatory disease. Immunobiology 215: 611-616.

18. Ambrosio AL, Dias SM, Polikarpov I, Zurier RB, Burstein SH, et al. (2007) Ajulemic acid, a synthetic nonpsychoactive cannabinoid acid, bound to the ligand binding domain of the human peroxisome proliferator-activated receptor gamma. J Biol Chem 282: 18625-18633.

19. Burnette-Curley D, Cabral GA (1995) Differential inhibition of RAW264.7 macrophage tumoricidal activity by delta 9tetrahydrocannabinol. Proc Soc Exp Biol Med 210: 64-76.

20. Facchinetti F, Del Giudice E, Furegato S, Passarotto M, Leon A (2003) Cannabinoids ablate release of TNFalpha in rat microglial cells stimulated with lypopolysaccharide. Glia 41: 161-168.

21. Molina-Holgado F, Lledo A, Guaza C (1997) Anandamide suppresses nitric oxide and TNF-alpha responses to Theiler's virus or endotoxin in astrocytes. Neuroreport 8: 1929-1933.

22. Molina-Holgado F, Molina-Holgado E, Guaza C, Rothwell NJ (2002) Role of $\mathrm{CB} 1$ and $\mathrm{CB} 2$ receptors in the inhibitory effects of cannabinoids on lipopolysaccharide-induced nitric oxide release in astrocyte cultures. J Neurosci Res 67: 829-836.

23. Klein TW, Lane B, Newton CA, Friedman H (2000) The cannabinoid system and cytokine network. Proc Soc Exp Biol Med 225: 1-8.

24. Pryce G, Ahmed Z, Hankey DJ, Jackson SJ, Croxford JL, et al. (2003) Cannabinoids inhibit neurodegeneration in models of multiple sclerosis. Brain126: 2191-2202.

25. Ni X, Geller EB, Eppihimer MJ, Eisenstein TK, Adler MW, et al. (2004) Win 55212-2, a cannabinoid receptor agonist, attenuates leukocyte/endothelial interactions in an experimental autoimmune encephalomyelitis model. Mult Scler 10: 158-164.

26. Kubajewska I, Constantinescu CS (2010) Cannabinoids and experimenta models of multiple sclerosis. Immunobiology 215: 647-657.

27. Ortega-Gutiérrez S, Molina-Holgado E, Arévalo-Martín A, Correa F, Viso A, et al. (2005) Activation of the endocannabinoid system as therapeutic approach in a murine model of multiple sclerosis. Faseb J 19: 1338-1340.

28. Loría F, Petrosino S, Mestre L, Spagnolo A, Correa F, et al.(2008) Study of the regulation of the endocannabinoid system in a virus model of multiple sclerosis reveals a therapeutic effect of palmitoylethanolamide. Eur J Neurosci 28: 633 641

29. Loría F, Petrosino S, Hernangómez M, Mestre L, Spagnolo A, et al. (2010) An endocannabinoid tone limits excitotoxicity in vitro and in a model of multiple sclerosis. Neurobiol Dis 37, 166-176.

30. Honegger P, Lenoir D, Favrod P (1979) Growth and differentiation of aggregating fetal brain cells in a serum-free defined medium. Nature 282:305308.

31. Matthieu JM, Honegger P, Favrod P, Gautier E, Dolivo M (1979) Biochemical characterization of a myelin fraction isolated from rat brain aggregating cel cultures. J Neurochem 32: 869-881.

32. Defaux A, Zurich MG, Honegger P, Monnet-Tschudi F (2010) Inflammatory responses in aggregating rat brain cell cultures subjected to different demyelinating conditions. Brain Res 1353: 213-224.

33. Paul Honegger and Florianne Monnet-Tschudi (2001) Aggregating neural cel cultures: Totowa, NJ. 199-218 p.

34. Monnet-Tschudi F, Hazekamp A, Perret N, Zurich MG, Mangin P, et al. (2008) Delta-9-tetrahydrocannabinol accumulation, metabolism and cell-type-specific adverse effects in aggregating brain cell cultures. Toxicol Appl Pharmacol 228 8-16.

35. Zurich MG, Lengacher S, Braissant O, Monnet-Tschudi F, Pellerin L (2005) Unusual astrocyte reactivity caused by the food mycotoxin ochratoxin $A$ in aggregating rat brain cell cultures. Neuroscience 134: 771-782.

36. Cagnon L, Braissant O (2009) CNTF protects oligodendrocytes from ammonia toxicity: intracellular signaling pathways involved. Neurobiol Dis 33: 133-142.

37. Streit, W. J. and Kreutzberg, G. W. (1987) Lectin binding by resting and reactive microglia. J Neurocytol 16: 249-260.

38. Defaux A, Zurich MG, Honegger P, Monnet-Tschudi F (2011) Minocycline 
Citation: Defaux A, Schiffrin M, Vorlet-Fawer L, SpiehImann A, Giroud C, et al. (2012) Delta-9-Tetrahydrocannabinol (THC) Protects Partly against Demyelination by Modulating the Inflammatory Response: An In Vitro Study in Aggregating Brain Cell Cultures. J Clinic Toxicol S6:002. doi:10.4172/2161-0495.S6-002

Page 8 of 8

promotes remyelination in aggregating rat brain cell cultures after interferongamma plus lipopolysaccharide-induced demyelination. Neuroscience 187 84-92.

39. Lakhan, S E and Rowland, M (2009) Whole plant cannabis extracts in the treatment of spasticity in multiple sclerosis: a systematic review. BMC Neuro 9: 59.

40. Rog, DJ (2010) Cannabis-based medicines in multiple sclerosis--a review of clinical studies. Immunobiology 215: 658-672.

41. Zajicek, J. P. and Apostu, VI (2011) Role of cannabinoids in multiple sclerosis. CNS Drugs 25: 187-201.

42. Koistinaho M, Koistinaho J (2002) Role of p38 and p44/42 mitogen-activated protein kinases in microglia. Glia 40: 175-183.

43. Bhat NR, Zhang P, Lee JC, Hogan EL (1998) Extracellular signal-regulated kinase and p38 subgroups of mitogen-activated protein kinases regulate inducible nitric oxide synthase and tumor necrosis factor-alpha gene expression in endotoxin-stimulated primary glial cultures. J Neurosci 18: 1633-1641.

44. Uesugi M, Nakajima K, Tohyama Y, Kohsaka S, Kurihara T (2006) Nonparticipation of nuclear factor kappa B (NFkappaB) in the signaling cascade of c-Jun N-terminal kinase (JNK)- and p38 mitogen-activated protein kinase (p38MAPK)-dependent tumor necrosis factor alpha (TNFalpha) induction in lipopolysaccharide (LPS)-stimulated microglia. Brain Res 1073-1074: 48-59.

45. Park JS, Woo MS, Kim SY, Kim WK, Kim HS (2005) Repression of interferongamma-induced inducible nitric oxide synthase (iNOS) gene expression in microglia by sodium butyrate is mediated through specific inhibition of ERK signaling pathways. J Neuroimmunol 168: 56-64.

46. Bass CE, Martin BR (2000) Time course for the induction and maintenance of tolerance to Delta(9)-tetrahydrocannabinol in mice. Drug Alcohol Depend 60: 113-119.

47. Breivogel CS, Selley DE, Childers SR (1998) Cannabinoid receptor agonist efficacy for stimulating [35S]GTPgammaS binding to rat cerebellar membranes correlates with agonist-induced decreases in GDP affinity. J Biol Chem 273: 16865-16873.
48. Romero-Sandoval EA, Horvath R, Landry RP, DeLeo JA (2009) Cannabinoid receptor type 2 activation induces a microglial anti-inflammatory phenotype and reduces migration via MKP induction and ERK dephosphorylation. Mol Pain 5: 25 .

49. Bernardo A, Levi G, Minghetti L (2000) Role of peroxisome proliferator-activated recepor-y (PPAR-g) and its natural ligand 15-deoxy-D12,14-prostaglandin J2 in the regulation of microglial functions. Eur. J. Neurosc 12: 2215-2223.

50. Dello Russo C, Gavrilyuk V, Weinberg G, Almeida A, Bolanos JP, Palmer J, Pelligrino D, Galea E, Feinstein D (2003) Peroxisome proliferator-activated receptor gamma thiazolidinedione agonists increase glucose metabolism in astrocytes. J Biol Chem 278: 5828-5836.

51. Woster AP, Combs CK (2007) Differential ability of a thiazolidinedion PPARgamma agonist to attenuate cytokine secretion in primary microglia and macrophage-like cells. J Neurochem 103: 67-76.

52. Delerive P, Fruchart J-C, Staels B (2001) Peroxisome proliferator-activated receptors in inflammation control. J. Endocrinol 169: 453-459.

53. Daynes RA, Jones DC (2002) Emerging roles of PPARs in inflammation and immunity. Nature Reviews 2: 748-759.

54. Janabi N, Di Stefano M, Wallon C, Hery C, Chiodi F, et al. (1998) Induction of human immunodeficiency virus type 1 replication in human glial cells afte proinflammatory cytokines stimulation: effect of IFNgamma, IL1beta, and TNFalpha on differentiation and chemokine production in glial cells. Glia 23: 304-315.

55. Zemke D, Majid, A (2004) The potential of minocycline for neuroprotection in human neurologic disease. Clin Neuropharmacol 27: 293-298.

56. Defaux A, Zurich MG, Braissant O, Honegger P, Monnet-Tschudi F (2009) Effects of the PPAR-beta agonist GW501516 in an in vitro model of brain inflammation and antibody-induced demyelination. J Neuroinflammation 6:15.

57. Bisogno, T and Di Marzo, V (2010) Cannabinoid receptors and endocannabinoids: role in neuroinflammatory and neurodegenerative disorders. CNS Neurol Disord Drug Targets 9: 564-573.
This article was originally published in a special issue, Neuropharmacology \& Neurotoxicity handled by Editor(s). Dr. Terreia S Jones, University of Tennessee Health Science Center, USA
Submit your next manuscript and get advantages of OMICS Group submissions

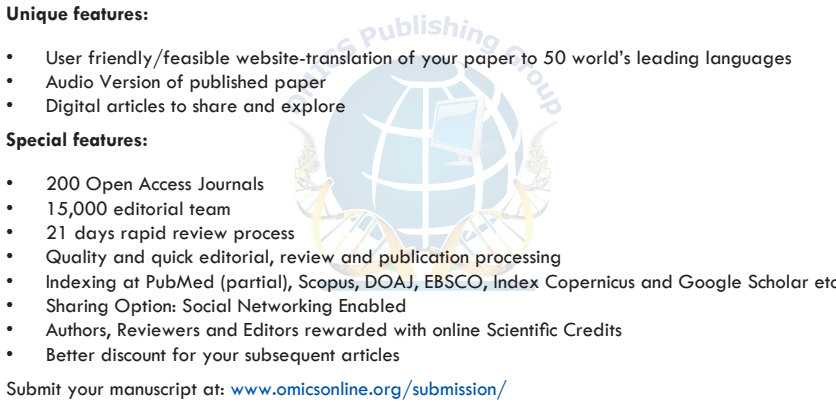

Submit your manuscript at: www.omicsonline.org/submission/ 